\title{
New name proposed for popular sweetener
}

Published at www.cmaj.ca on Sept. 23

$\mathrm{W}$ hat's in a name? A whole lot of negativity, if the name is "high-fructose corn syrup." That's why the Corn Refiners Association - a trade association based in Washington, DC, that represents the corn refining industry wants to change that name. It has petitioned the United States Food and Drug Administration (FDA) to permit food manufacturers to use the name "corn sugar" instead. Even dieticians and nutritionists, though reluctant to side with a group promoting a highcalorie sweetener, admit that highfructose corn syrup has been inaccurately pegged as being more harmful to the body than other sugars.

"I understand where they are coming from," says Jennifer Sygo, a registered dietician and director of nutrition for Cleveland Clinic Canada in Toronto, Ontario. "High-fructose corn syrup has been painted a bit unfairly, but we have to be cautious to severely limit all added sugars."

Honey, sucrose (table sugar) and fruit-juice concentrates have just as many calories as high-fructose corn syrup, though many in the public appear to think otherwise. Highfructose corn syrup doesn't even contain more fructose (the sugar found naturally in fruits) than table sugar. The name "high-fructose corn syrup" was created to distinguish the product from regular corn syrup, which is composed mostly of glucose (which is produced in the US primarily through the hydrolysis of starch obtained from corn).

Makers of high-fructose corn syrup probably just want to level the playing field with makers of other types of sweeteners, says Sygo, which is not unreasonable. "There are other sugars that contain comparable amounts of fructose that haven't been painted with the same broad brush. We can't treat it as the one and only sugar to worry about," she says. "But we don't want to

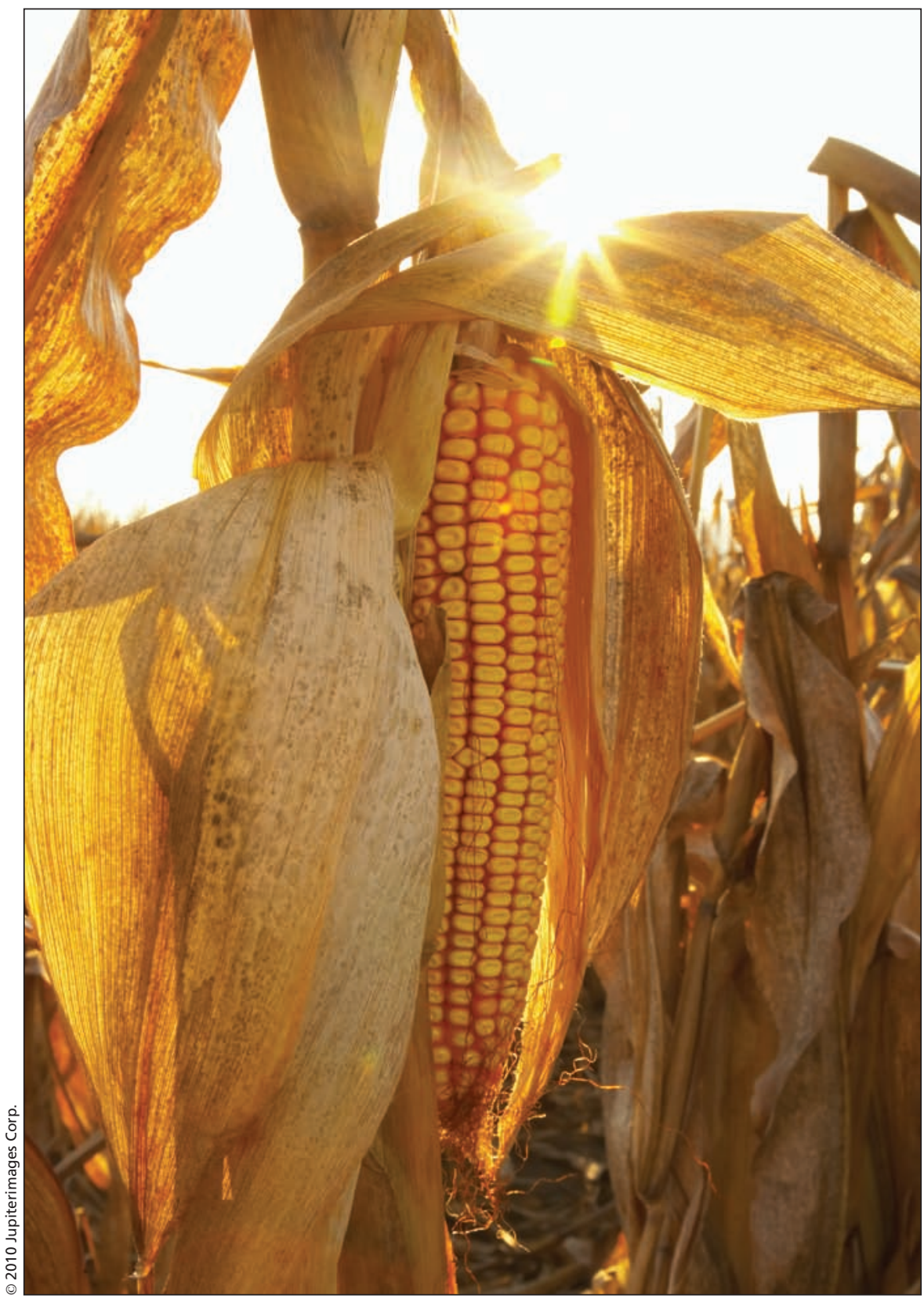

Regular corn syrup, which consists mostly of glucose, is made by milling corn into a starch and then processing it. Adding enzymes to the corn syrup changes much of the glucose to fructose, producing the ubiquitous sweetener called high-fructose corn syrup.

create the impression that it's natural and therefore it's healthy."

One possible reason that highfructose corn syrup has gained a bad reputation is because it has grown in popularity in recent decades and is now found in a wide array of high-calorie foods, including cookies, breakfast cereals and soft drinks. It has therefore been linked to obesity and obesity-related illnesses, such as diabetes. Food manufacturers often prefer high-glucose corn 
syrup to sucrose because it is better at retaining moisture and it doesn't mask flavours. Lower prices resulting from heavy subsidization of corn growers help make it attractive to food makers.

The bad reputation of the ubiquitous sweetener is unjustified, says Audrae Erickson, president of the Corn Refiners Association. Her group has petitioned for a new name for high-fructose corn syrup to clear up consumer confusion, she says, and to educate people on what is in their food. Just having the word "high" in the name gives people the impression that it is higher in calories and fructose concentration than other types of sugar, she says, though that isn't true. People also tend to think that high-fructose corn syrup is sweeter tasting than other types of sugar, says Erickson, but that is also false.

"High-fructose corn syrup is similar in composition to table sugar," says Erickson. "It doesn't contribute to disease or obesity any more than table sugar."

The Corn Refiners Association, which submitted the name-change petition on Sept. 14, is expected to receive a response from the FDA within six months. If the response is positive, it may take up to 18 months before US food manufacturers are permitted to use the term "corn sugar" on labels.

Though uncommon, name changes to food products aren't unheard of. In 1988, for example, the FDA allowed low erucic acid rapeseed oil to be renamed as "canola oil" and, in 2000, permitted prunes to be called "dried plums."

According to Doug Cook, a Toronto-based registered dietician, the Corn Refiners Association does not appear to be attempting to mislead the public in seeking a name change for high-fructose corn syrup. But promoting the product as a natural ingredient made from corn, though technically correct, is another matter. "Natural doesn't mean good," says Cook. "At the end of the day, there is still too much sugar being consumed. Consumption of all added sugars needs to be reduced." — Roger Collier, CMAJ

DOI:10.1503/cmaj.109-3681 